Concussion in children

\title{
Can we manage sport related concussion in children the same as in adults?
}

\section{P McCrory, A Collie, V Anderson, G Davis}

Evidence based guidelines are required for the management of concussive injury in children

\begin{abstract}
C onsensus guidelines for managing sport related concussion in adults mave been increasingly widely implemented. ${ }^{1}$ So far, there are no guidelines that enable clinicians to manage similar sporting concussive injuries in children. Furthermore, there are a number of important anatomical, physiological, and behavioural differences between adults and children that suggest that adult guidelines will need to be either modified or rewritten to manage injuries in this age group.
\end{abstract}

\section{EPIDEMIOLOGY OF CONCUSSION IN CHILDREN}

The annual incidence of traumatic brain injury (TBI) in adults is remarkably constant worldwide and has been estimated at between 180 and 300 cases per 100000 population. ${ }^{2-5}$ This is believed to be an underestimate of the true incidence as an equivalent number of mild injuries are treated by general practitioners and do not result in hospital admission. ${ }^{6}$ Direct sport participation accounts for approximately $15-20 \%$ of all such $\mathrm{TBI}^{37}$ and in children a further smaller percentage of TBI is associated with play activities. ${ }^{8}$

In children aged 15 years and under, the estimated incidence rate of TBI is 180 per 100000 children per year of which approximately $85 \%$ are categorised as mild injuries. ${ }^{7}$ In the US, it has been estimated that more than 1 million children sustain a TBI annually and that TBI accounts for more than 250000 paediatric hospital admissions as well as more than $10 \%$ of all visits to emergency service settings.'

In child and adolescent populations, few well controlled studies exist to identify the age specific frequency and outcome of sport related concussive injuries.

\section{INTRINSIC DIFFERENCES BETWEEN CHILD AND ADULT CONCUSSION}

The most common cognitive sequelae of concussive injuries in children are the same as for adults, namely reduced speed of information processing, poor attention, and impaired executive function. ${ }^{10-14}$ Concussion may also have a significant negative secondary impact upon educational and social attainment, as these processes are critical for performing common day to day activities in childhood and adolescence, such as acquiring new knowledge and attending to school work. The nature, magnitude, and duration of these post-concussion cognitive impairments are yet to be determined, and the academic and social consequence for the child remains unknown at this time. In addition, it has been reported that children may suffer from a variety of post-concussion behavioural sequelae despite normal neuropsychological testing. ${ }^{15}$

It is also known that brain tolerance to biomechanical forces differs between adults and children. ${ }^{16}$ In broad terms, a two to three fold greater impact force is required to produce clinical symptoms in children compared to adults. This is due to a combination of factors, including an age dependent physiological response to mechanical stress, the differing geometry of the skull and brain, and the constitutive structural properties of the head. This means that if a child exhibits clinical symptoms after head injury, then it is reasonable to assume that they have sustained a far greater impact force compared to an adult with the same postconcussive symptoms.

There are rare but well recognised post-traumatic clinical sequelae that occur predominantly in children and teenagers, such as diffuse cerebral swelling. ${ }^{17-20}$ The concussive impact, however trivial, sets in train the rapid development of cerebral swelling that usually results in brainstem herniation and death. Its cause is unknown but is thought to involve disordered cerebral vascular autoregulation. Although repeated concussive injuries have been proposed as the basis for this syndrome (the so called second impact syndrome), the evidence for repeated concussion as a specific risk factor is not compelling. ${ }^{21}$ It is more likely that a single impact of any severity may result in this rare complication; however, participation in sport simply draws attention to incidental concussive injuries in this setting. There is also limited published evidence that a specific genetic abnormality predisposes to brain swelling following mild head injury in children. ${ }^{22}$

\section{NEUROPSYCHOLOGICAL DIFFERENCES BETWEEN CHILDREN AND ADULTS}

Over and above any cognitive effects of concussion, there is an additional issue that makes assessment difficult, namely the fact that the brain is cognitively maturing during this period. This has two major implications. Firstly, the child's brain potentially may be more vulnerable to the impact of head injury than the more mature adult brain due to the disturbances of neuronal maturation caused by brain trauma. ${ }^{14}$ Secondly, unlike adults where cognitive function is relatively stable over time, children's cognition continues to develop. Thus any assessment of baseline or post-injury cognitive function needs to factor in the normal maturation in cognition that is occurring over this period. Pilot unpublished cross sectional data collected in 180 healthy children using a computerised cognitive test paradigm (CogSport) indicates substantial improvement in performance between the ages of 9 and 18 years on tests of simple and choice reaction time, working memory, and new learning. The largest improvements in test performance occur between the ages of 9 and 15, with minimal changes after this age paralleling adult performance (fig 1 ).

These developmental changes are of comparable magnitude to post-concussive impairments observed on computerised cognitive post-injury assessment in adults. ${ }^{23}{ }^{24}$ This has the potential for confusion in assessment given that maturational improvements occurring between baseline and post-concussion testing may offset any injury related cognitive impairment in concussed children and adolescents.

\section{RISK FACTORS FOR SEQUELAE AND POOR RECOVERY AFTER CONCUSSION IN CHILDREN}

It has been argued that individuals are not at equal risk for symptoms and cognitive dysfunction following concussion, and also that some individuals may be at higher risk of sustaining concussion than others. There is circumstantial evidence that a prior history of brain injury is a risk factor for subsequent concussive injury in children. $^{1525}$

Other potential risk factors that may predict more severe neurobehavioral 


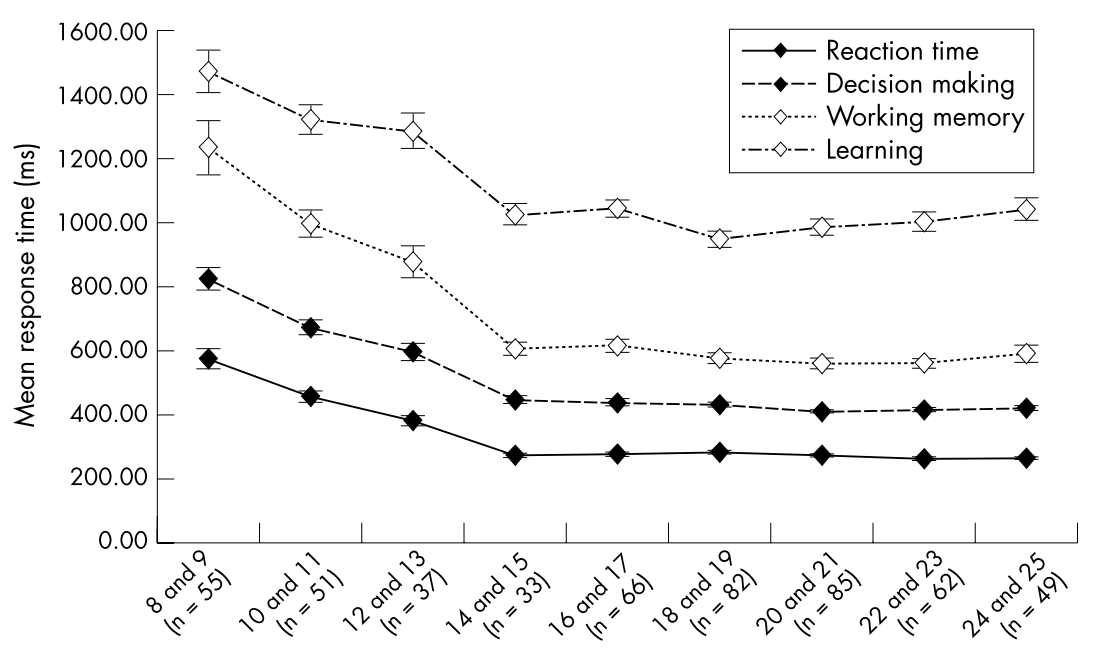

Age group

Figure 1 Mean (and standard error) response speed on four cognitive tasks in nine different age bands, from 8 to 25 years of age.

sequelae following injury, especially in younger children where the brain is less mature, include the presence of premorbid cognitive, attention, and behavioural impairments. ${ }^{15} 26$

It has also become a widely held belief that having sustained a sport related concussive injury, an athlete is then more prone to future concussive injury. The evidence for this in sport is limited with most studies being methodologically flawed. ${ }^{27-29}$ It has been suggested that individuals with more aggressive playing styles may be at the greatest risk of concussion.

Although helmet use may be effective in preventing superficial head injury in children, its role in preventing concussion and other forms of traumatic brain injury remains unproven. Furthermore, recent studies have shown a differential behavioural response of children to protective equipment with some adopting increased risk taking behaviour and hence paradoxically increasing their risk of sustaining a concussive injury by wearing a "protective" helmet. ${ }^{30} 31$

There is also evidence that an individual's genetic make up may predict outcome from head injury. In particular, an association has been identified between the apolipoprotein E $\epsilon 4$ allele and poor clinical outcome in adult patients with mild head injury. ${ }^{32}$ Although only in the early stages of understanding, the interaction between genetic and environmental factors may be critical in the development of post-concussive phenomena. These data suggest that it may be possible to identify individuals who are at greater risk for poor outcomes from concussion and in the future management practices may need to be tailored to incorporate such information.

\section{CAN WE USE ADULT CONCUSSION RETURN TO PLAY STRATEGIES IN CHILDREN?}

There have been numerous attempts in the past to formulate evidence based concussion management guidelines, ${ }^{33}$ with that developed at the recent Vienna Consensus Conference ${ }^{1}$ being most widely accepted today. In broad terms, this approach recommends baseline cognitive testing to enable accurate individual assessment of recovery, in order to guide return to play following concussion.

There are no current guidelines for diagnosis and management of concussion in children beyond generic recommendations for observation and neuroimaging following childhood mild head injury. ${ }^{34}$ This is also reflected in the variable specialist clinical management that may be offered in this situation. In a recent pilot study of paediatric neurosurgical management of sport related concussive injury in children, there was no consensus between the surgeons being studied as to the significance of specific clinical symptoms or on recommendations regarding hospitalisation, time off school and sport, or the use of protective equipment following injury. ${ }^{35}$

The "comparison to own baseline" model of assessment remains a powerful method of assessing change in cognitive function after concussion, and in the absence of conflicting evidence, should be adopted as a conservative approach to identifying postconcussion cognitive deficits in children as it is in adults. The central issue is how often baseline testing should be conducted. During the period of rapid cognitive maturation (8-15 years of age), baseline testing would have to be performed at least 6 monthly to enable accurate comparison for serial testing. Apart from elite junior athletes, such regular testing would be beyond the resources of most sports and individuals. For any child or adolescent athlete participating in collision sport or where there is a significant risk of concussion, annual cognitive testing should be considered. Any statistical decision about whether cognition has changed from baseline following concussion must also include an adjustment for developmental changes in cognition. This in turn requires knowledge of how performance changes on specific tests over time. Figure 1 demonstrates the cognitive maturation process that is maximal between 8 and 15 years of age and gives an estimate of the degree of this change. Beyond 15 years of age an annual baseline test would be suitable, as for adult athletes, and be applied in the same fashion as for adults and without any developmental increment.

\section{THE CLINICAL MANAGEMENT OF CONCUSSION IN CHILDREN}

Current adult management of concussion involves an initial diagnosis using a validated assessment tool such as the Maddocks questions ${ }^{36}$ or the Standardized Assessment of Concus$\operatorname{sion}^{37}$. Neither tool has been specifically tested or validated in children with concussion.

One preliminary study suggests that high school aged children (14-18 years) may also have prolonged cognitive recovery when compared with young adults (18-25 years), but that symptom recovery is equivalent between these groups. ${ }^{38}$ This finding raises the possibility that symptom ratings and cognitive testing may be differentially sensitive to concussion in minors and adults; however, there is no such information available for younger children. This in turn raises concern as to how sport related concussion assessment may be performed in these age groups and the validity of existing assessment tools.

Return to play concussion guidelines recommend baseline cognitive evaluation of all individuals participating in contact and collision sport. ${ }^{1}$ The heterogeneity of concussion ensures that individual comparison to baseline allows more sensitive identification of post-concussion symptom elevation and cognitive dysfunction than arbitrary classification according to a retrospective grading scale..$^{39} 40$

Statistical models used to determine the significance of any observed postconcussion cognitive change require knowledge of how cognitive test performance and symptom ratings change in 
healthy, uninjured individuals. ${ }^{41}$ In adult populations (and potentially children aged 16 years and over) available data suggest that cognitive performance remains relatively stable over time on tests commonly used in concussion management. ${ }^{42}$

These findings support the need for prospective serial investigation of cognitive and behavioural function in healthy and concussed children and adolescents, including specific assessment of how cognitive processes (including response variability) change within individuals. Such data will be invaluable in informing the development of concussion management guidelines in this population, and the interpretation of postconcussion cognitive test data.

The issue of neuroimaging is often raised for children following mild head injury. With young patients, this issue is often problematic given that they may require a general anaesthetic in order to obtain adequate images, although new generation spiral CT scanners are able to perform extremely rapid imaging sequences. If imaging is desired by the health practitioner in this setting or by the subsequent development of symptoms of intracranial pathology, then CT scanning is the imaging modality of choice in the emergency setting. The American Academy of Paediatrics guidelines state that there is no indication for routine use of skull $x$ ray in paediatric concussion and "no data are available that demonstrate that children who undergo CT scanning early after minor closed head injury with loss of consciousness have different outcomes compared with children who receive observation alone after injury". ${ }^{34}$

In broad terms, a previously neurologically healthy child with a concussive injury who has normal mental status, no abnormal or focal abnormalities on neurological exam, and no physical evidence of skull fracture simply requires observation by a competent caregiver. The risk of clinically significant intracranial pathology in this setting is less than $0.02 \%^{34}$ although earlier studies had suggested higher figures. ${ }^{44}{ }^{45}$ It is likely that many of these early studies suffered from selection bias and over estimated this risk in this situation. ${ }^{34}$

\section{SUMMARY}

At the present time, there are no evidence based guidelines using which sport related concussive injury in childhood and adolescence can be scientifically managed. There are significant differences between adults and children in this regard and a child who is symptomatic following head injury is likely to have sustained a far greater impact force as compared to an adult with the same post-concussive symptoms.

The extent and duration of the cognitive effect on children with acute concussive injuries is variable and there may be persistent effects on scholastic performance and behaviour long after the clinical concussive symptoms and measurable neuropsychological impairment have resolved. Even subtle and transient impairments in attention and information processing skills can have a dramatic effect on the young person's capacity to cope with school demands, with these issues being particularly critical for those at later secondary school levels.

Based on pilot data, cognitive maturation is greatest in those under 15 years of age and beyond this time plateaus to an adult level of performance. Although comparison to baseline cognitive performance remains a powerful method of assessing function following a concussion injury, its application in children under 15 years of age is problematic given the rapid cognitive maturation that is occurring in this period. With regular baseline testing, an "adult" management strategy could be adopted in this age group, whereas in its absence only an estimate of normal age related cognitive function can be made. Beyond 15 years of age, it would be reasonable to follow the adult concussion management consensus guidelines utilising a "return to baseline" approach.

It is suggested that concussive symptoms take longer to resolve than in adults although this may be a surrogate marker of the biomechanical differences between child and adult concussion as outlined above. It is critical therefore that concussed children and adolescents not resume sport, school, or training until all the physical symptoms fully resolve. This is important also because of the risk of diffuse cerebral swelling that may occur in children after a single head injury no matter how trivial the impact may be. The adoption of a conservative adult management strategy with a thorough assessment of symptom resolution followed by "return to baseline" cognitive function remains the most appropriate management strategy in this age group.

Further research is required to characterise the duration and nature of the subclinical cognitive impairment that may exist during this recovery period in children. Increased awareness of these issues by those involved in the management of a child with concussion may assist in avoiding problems caused by this putative impairment.

Br J Sports Med 2004;38:516-519. doi: 10.1136/bjsm.2004.014811
Authors' affiliations

P McCrory, Centre for Health, Exercise and Sports Medicine and the Brain Research Institute, University of Melbourne, Parkville, Victoria 3010, Australia

A Collie, CogState Ltd, Carlton South, Victoria 3053, Australia

A Collie, Centre for Neuroscience, University of Melbourne, Parkville, Victoria 3010, Australia

V Anderson, Department of Psychology, Royal Children's Hospital, Parkville, Victoria 3052, Australia

G Davis, Department of Neurosurgery, Austin and Repatriation Medical Centre, Heidelberg, Victoria 3084, Australia

Correspondence to: Associate Professor Paul McCrory, Editor, British Journal of Sports Medicine, 200 Berkeley Street, Carlton,

Victoria 3053, Australia; pmccrory@ compuserve.com

\section{REFERENCES}

1 Aubry M, Cantu R, Dvorak J, et al. Summary and agreement statement of the first International Conference on Concussion in Sport, Vienna 2001. Br J Sports Med 2002;36:6-10.

2 Annegers J, Hauser W, Coan S, et al. A population based study of seizures after traumatic brain injuries. N Engl J Med 1998;338:20-4

3 Jennett B. Epidemiology of head injury. J Neurol Neurosurg Psychiatr 1996;60:362-9.

4 Tate R, McDonald S, Lulham J. Incidence of hospital-treated traumatic brain injury in an Australian community. Aust N Z J Public Health 1998;22(4):419-23.

5 Alexander M. Mild traumatic brain injury. Neurology 1995;45: 1253-60.

6 Wrightson P, Gronwall D. Mild head injury in New Zealand: incidence of injury and persisting symptoms. N Z Med J 1998;111:99-101.

7 Kraus JF. Epidemiological features of brain injury in children: occurrence, children at risk, causes and manner of injury, severity and outcomes. In: Broman S, Michel M, eds. Traumatic head injury in children. New York: Oxford University Press, 1995:22-39

8 Clapperton A, Cassell E, Wallace A. Injury to children aged 5-15 years at school. In: MUARC, ed. Hazard. Victorian Injury Surveillance and Applied Research System. Melbourne, Australia: Monash University Accident Research Centre, 2003:1-16.

9 Yeates K, Luria J, Bartkowski $\mathrm{H}$, et al. Postconcussive symptoms in children with mild closed head injuries. J Head Trauma Rehabil 1999: 14:337-50.

10 Collie A, Darby D, Maruff P. Computerised cognitive assessment of athletes with sportsrelated head injury. Br J Sports Med 2001;35(5):297-302.

11 Echemendia R, Julian L. Mild traumatic brain injury in sports: neuropsychology's contribution to a developing field. Neuropsychol Rev 2001;11(2):69-99.

12 Macciocchi SN, Barth JT, Alves W, et al. Neuropsychological functioning and recovery after mild head injury in collegiate athletes. Neurosurgery 1996;39(3):510-4.

13 Maddocks D, Dicker G. An objective measure of recovery from concussion in Australian rules footballers. Sport Health 1989;7(suppl):6-7.

14 Anderson V. Outcome from mild head injury in young children: a prospective study. J Clin Exp Neuropsychol 2001;23(6):705-17.

15 Ponsford J, Willmott C, Rothwell A, et al. Cognitive and behavioral outcome following mild traumatic head injury in children. J Head Trauma Rehabil 1999;14(4):360-72.

16 Ommaya AK, Goldsmith W, Thibault L. Biomechanics and neuropathology of adult and paediatric head injury. Br J Neurosurg 2002; 16(3):220-42. 
17 Bruce DA, Alavi A, Bilaniuk L, et al. Diffuse cerebral swelling following head injuries in children: the syndrome of 'malignant brain oedema'. J Neurosurg 1981;54(2):170-8.

18 Bruce DA. Delayed deterioration of consciousness after trivial head injury in childhood. $\mathrm{Br}$ Med J 1984;289:715-6.

19 Pickles W. Acute general edema of the brain in children with head injuries. N Engl J Med 1950;242:607-11.

20 Snoek JW, Minderhoud JM, Wilmink JT. Delayed deterioration following mild head injury in children. Brain 1984;107:15-36.

21 McCrory P, Berkovic SF. Second impact syndrome. Neurology 1998;50(3):677-84.

22 Kors E, Terwindt G, Vermeulen F, et al. Delayed cerebral edema and fatal coma after minor head trauma: role of the CACNA1A calcium channel subunit gene and relationship with familial hemiplegic migraine. Ann Neurol 2001;49:753-60.

23 Bleiberg J. Consistency of within-day and acrossday performance after mild brain injury. Neuropsychiatry Neuropsychol Behav Neurol 1997; 10(4):247-53

24 Makdissi M, Collie A, Maruff P, et al. Computerised cognitive assessment of concussed Australian rules footballers. Br J Sports Med 2001;35(5):3543-60

25 Rutter M, Chadwick O, Shafgfer D. Head injury. In: Rutter $M$, eds. Developmental neuropsychiatry. New York: Guilford Press, 1983:77-83.

26 Lovell $M$, Iverson $G$, Collins $M$, et al. Does loss of consciousness predict neuropsychological decrements after concussion? Clin J Sport Med 1999;9:193-9.
27 Gerberich SG, Priest JD, Boen JR, et al. Concussion incidences and severity in secondary school varsity football players. Am J Public Health 1983:73(12):1370-5.

28 Albright $\mathrm{J}$. Head and neck injuries in college football. An eight year analysis. Am J Sports Med 1985; 13:147-52.

29 Guskiewicz KM, McCrea M, Marshall SW, et al. Cumulative effects associated with recurrent concussion in collegiate football players. JAMA 2003;290(19):2549-55.

30 Finch C, Mclntosh A, McCrory P. What do under 15 year old schoolboy rugby union players think about protective headgear? Br J Sports Med 2001;35:89-95.

31 Finch C, Mcintosh AS, McCrory P, et al. A pilot study of the attitudes of Australian Rules footballers towards protective headgear. J Sci Med Sport 2003;6(4):505-11.

32 Liberman J, Stewart W, Wesnes K, et al. Apolipoprotein $\mathrm{E} \mathrm{e} 4$ and short term recovery from predominantly mild brain injury. Neurology 2002; 58:1038-44

33 McCrory P, Johnston K, Meeuwisse W, et al. Evidence based review of sport related concussion: basic science. Clin J Sport Med 2001;11:160-6.

34 American Academy of Pediatrics. The management of minor closed head injury in children. Pediatrics 1999; 104(6):1407-15.

35 Davis G, McCrory $\mathrm{P}$. The paediatric sport-related concussion pilot study. Br J Sports Med 2004 (in press).

36 Maddocks DL, Dicker GD, Saling MM. The assessment of orientation following concussion in athletes. Clin J Sport Med 1995:5(1):32-5.
37 McCrea M, Kelly J, Randolph C, et al. Standardised assessment of concussion (SAC): on site mental status evaluation of the athlete. $J$ Head Trauma Rehabil 1998;13:27-36.

38 Field $M$. Does age play a role in recovery from sports-related concussion? A comparison of high school and collegiate athletes. J Pediatr 2003; 142(5):546-53.

39 Collie A, Maruff P, McCrory P, et al Statistical procedures for determining the extent of cognitive change following concussion. $\mathrm{Br} J$ Sports Med 2004;38(3):273-8

40 Johnston K, McCrory P, Mohtadi N, et al. Evidence based review of sport-related concussion - clinical science. Clin J Sport Med 2001;11:150-60.

41 Collie A, Maruff P, McStephen M, et al. The effects of practice on the cognitive test performance of neurologically normal individuals assessed at brief test-retest intervals. $J$ Int Neuropsychol Soc 2003;9(3):419-28.

42 Collie A, Maruff P, Makdissi M, et al. CogSport: reliability and correlation with conventional cognitive tests used in post concussion medical evaluations. Clin J Sport Med 2003;13(1):28-33.

43 Teasdale G, Murray G, Anderson E. Risks of acute traumatic intracranial complications in hematoma in children and adults: implications for head injuries. Br Med J 1990;300:363-7.

44 Dacey RG Jr, Alves WM, Rimel RW, et al. Neurosurgical complications after apparently minor head injury. Assessment of risk in a series of 610 patients. J Neurosurg 1986;65(2):203-10.

45 Hahn Y, McLone D. Risk factors in the outcome of children with minor head injury. Pediatr Neurosurg 1993;19:135-42.

\section{Sport psychology and concussion: new impacts to explore}

\section{G A Bloom, A S Horton, P McCrory, K M Johnston}

n recent years, there has been great interest in examining the psychological effects of athletic injuries. This has also extended to interventions in which coping strategies have been suggested to enhance recovery. Concussive injuries, which are common to many sports, hold particular problems in this regard. For example, a concussed athlete may be prone to experience isolation, pain, anxiety, and disruption of daily life as a result of the injury. This may be a problem for individual sport athletesfor example, professional skiers-who do not have the support of team mates to help them through their rehabilitation and recovery, as well as team sport athletes whose team mates may inadvertently pressure them to return to play.

Besides the physical loss resulting from an injury, there may also be psychological distress. Commonly reported emotion responses resulting from athletic injury have included anger, denial, depression, distress, bargaining, shock, and guilt. ${ }^{1-5}$ These are particularly seen in career ending injuries. Such emotional distress can negatively affect the athletes' recovery process.

"...concussed athletes in team sports seem to have fewer long term problems"

Injured athletes have also reported feelings of isolation and loneliness. Researchers found that athletes prevented from participating in their activity have lost contact with their team, coach, and friends. ${ }^{67}$ For example, Gould et $a l^{6}$ examined the emotional reactions of US national team skiers to season ending injuries and found that $66.6 \%$ cited lack of attention and isolation as a source of stress during their injury. In another study of injured athletes, Brewer et al ${ }^{2}$ surveyed 43 sports medicine practitioners to discover side effects of psychological distress. These side effects included exercise addiction, weight control problems, family adjustment, and substance abuse. These problems have been reported individually as well as being associated with depression and anxiety and have been shown to cause severe health complications. ${ }^{7}$

Injured athletes have reported different levels of satisfaction with the social support they have received after injury. In particular, team mates have been shown to have a greater affect on the emotional state of injured athletes than coaches or medical professionals. ${ }^{8}$ This leads one to speculate that individual sport athletes may experience different adjustment difficulties while recovering from a concussion. This may also suggest why concussed athletes in team sports seem to have fewer long term problems, such as persistent post-concussive symptoms. In an environment in which team mates are likely to have experienced similar injuries, there is a greater corporate memory of such injuries and hence more reassurance as to the likely recovery time frame and validation of subjective symptoms experienced by the injured athlete.

\section{UNIQUENESS OF CONCUSSION INJURIES}

A number of unique characteristics of concussion injuries exist. Firstly, a concussion is an "invisible injury". This 
means there are no crutches, swelling, stitches, or other visual signs of the injury. This makes it very difficult for a casual observer to identify the athlete as injured. A second unique characteristic of concussion injuries is the overlap of post-concussive symptoms with psychological responses to injury. A third problem may be a loss of fitness (through loss of both aerobic and resistance training activity), particularly if the post-concussive symptoms persist. A fourth problem, unique to professional sport, is the relentless media commentary that typically occurs after injury. This increases pressure on injured athletes to regain their sporting place.

\section{"... it is often not considered accep- table to spend prolonged time reha- bilitating a concussion injury"}

Another issue surrounding concussion injuries is the lack of acceptance or understanding of long term rehabilitation. Whereas it is often considered necessary to rehabilitate an orthopaedic injury for a number of months, it is often not considered acceptable to spend prolonged time rehabilitating a concussion injury. This may result in more anxiety and frustration for the athlete and coach. Finally, concussion injuries are unique because there is at present no standard intervention technique. For most other injuries, rehabilitative treatments are available-for example, physiotherapy, medication, exercise, surgery, etc. However, this is not the case for concussion injuries; the athlete may leave the doctor with either no specific management or at best a minimally structured treatment plan.

\section{SOCIAL SUPPORT GROUPS}

It is not uncommon for people who have experienced life events such as addiction, illness of a family member, injury, or a significant loss to have difficulty dealing with the stress and anxiety of their situation. As a result of the distress encountered, different methods of coping and psychological support have been developed. Throughout the last 20 years, the role of social support in dealing with disease has increased significantly.? Support groups have been developed to educate, prevent isolation, and help in coping. ${ }^{10}$ Positive outcomes from support groups have been proven effective for sufferers of AIDS, ${ }^{11}{ }^{12}$ cancer, ${ }^{13}$ obsessive compulsive disorder, ${ }^{14}$ and pregnancy loss, ${ }^{15}$ and families of critically ill patients. ${ }^{16}$ It has also been shown that general social support is beneficial for athletes suffering from injuries. ${ }^{17}{ }^{18} \mathrm{~A}$ support group for injured athletes may also provide the same benefits as it has for non-athletic populations.

Intervention strategies and psychological rehabilitation techniques have included imagery, relaxation, modelling, goal setting, positive self talk, social support and support groups, pain management, simulation training, education, stress management, and cognitive reconstruction. ${ }^{519-24}$ Social support and communication have been two most commonly suggested rehabilitation strategies. Lynch ${ }^{22}$ stressed the importance of the sport psychologist in encouraging athletes to discuss their experiences with others. These interactions were designed to help reduce the injured athlete's feelings of isolation and loneliness.

\section{SOCIAL SUPPORT IN ATHLETIC INJURY REHABILITATION}

Two distinct types of social support have been used during injury rehabilitation in an athletic setting: support groups and peer modelling. ${ }^{45}$ Support groups for injured athletes have allowed injured athletes to come together to voice their concerns, share ideas about coping, learn vital performance enhancement strategies, and realise that they are not alone. ${ }^{4}$ The goal is that athletes will support one another both mentally and physically by helping deal with the demands of rehabilitation and not participating in their sport. ${ }^{20}$

Numerous studies on non-athletic populations have been published showing the benefits of support groups in reducing anxiety, depression, and isolation and enhancing coping strategies. ${ }^{11-1416}$ To date there have been very few academic sources that have addressed the use of support groups for athletic injury and only one for concussion. ${ }^{20-25}$ Granito et al ${ }^{20}$ offered anecdotal support for an injured athlete support group programme, and Horton et $a l^{25}$ attempted to determine if participation in social support groups could reduce negative psychological side effects in concussion. It was shown that participants in the experimental concussed group improved their mood state, reducing effects such as anger, confusion, frustration, anxiety, depression, and isolation.

Social support has also been proven to have a significant effect on rehabilitation adherence. Udry ${ }^{18}$ reported that the most discriminating factor for rehabilitation adherence was level of social support. Athletes who perceived social support for their rehabilitation had better rehabilitation adherence, higher levels of motivation, and adopted a goal mastery orientation towards their rehabilitation. $^{18}$

\section{SUMMARY}

The use of sport psychology techniques in the management of concussion may assist in solving some of the real and very practical problems facing clinicians, namely certain aspects of the postconcussive syndrome and the influence of anxiety and other adverse psychological states, which in turn may impact on injury outcome. Techniques derived from other areas of psychology such as peer modelling may be successfully used in this setting.

Br J Sports Med 2004;38:519-521.

doi: 10.1136/bjsm.2004.011999

\section{Authors' affiliations}

G A Bloom, A S Horton, K M Johnston,

McGill University, Montreal, Canada

P McCrory, University of Melbourne,

Melbourne, Australia

Correspondence to: Dr Johnston, Department of Neurosurgery, Kinesiology \& Physical Education, McGill University, McGill Sport Medicine Centre, 475 Pine Ave West, Montreal, Quebec, Canada H2W 1S4; Karen.Johnston@mcgill.ca

\section{REFERENCES}

1 Brewer BW, Linder DE, Phelps CM. Situational correlates of emotional adjustment to athletic injury. Clin J Sport Med 1995;5:241-5.

2 Brewer BW, Van Raalte JL, Linder DE. Role of the sport psychologist in treating injured athletes: a survey of sports medicine providers. J Appl Sport Psychol 1991;3:183-90.

3 Quinn AM, Fallon BJ. The changes in psychological characteristics and reactions of elite athletes from injury onset until full recovery. J Appl Sport Psychol 1999;11:210-29.

4 Weiss MR, Troxel RK. Psychology of the injured athlete. Athletic Training 1986;21:104-10.

5 Wiese DM, Weiss MR. Psychological rehabilitation and the physical injury: implications for the sports medicine team. Sport Psychol 1987;1:318-30.

6 Gould D, Udry E, Bridges D, et al. Stress encountered when rehabilitating from season ending ski injuries. Sport Psychol 1997; 1 1:361-78.

7 Petitpas A, Danish SJ. Caring for injured athletes. In Murphy SM, ed. Sport psychology interventions. Champaign, IL: Human Kinetics, 1995:225-81.

8 Udry E, Gould D, Bridges D, et al. People helping people? Examining the social ties of athletes coping with burnout and injury stress. Journal of Sport and Exercise Psychology 1997; 19:368-95.

9 Cohen S, Wills TS. Stress, social support, and the buffering hypothesis. Psychol Bull 1985;98:310-57.

10 Kates N. Support groups in psychiatry: an untapped resource. Can J Psychiatry 1995:40:367-8

11 DiPasquale JA. The psychological effects of support groups on individuals infected by the AIDS virus. Cancer Nurs 1990;13:278-85.

12 Ribble D. Psychological support groups for people with HIV infection and AIDS. Holist Nurs Pract 1989;3:52-62.

13 Deans G, Bennett-Emslie GB, Weir J, et al. Cancer support groups: who joins and why? Br J Cancer 1988;58:670-4.

14 Broatch JW. Obsessive-compulsive disorders: adding value to treatment through patient support groups. Int Clin Psychopharmacol 1996; 11:89-94.

15 Bonno C. Peer support network. In: Woods J, Esposito J, eds. Pregnancy loss: medical 
therapeutics and practical considerations. Lo Angeles: Williams \& Wilkins, 1987:225-47.

16 Acorn S. Head-injured survivors: caregivers and support groups. J Adv Nurs 1993; 18:39-45.

17 Green SL, Weinberg RS. Relationships among athletic identity, coping skills, social support, and the psychological impact of injury in recreational participants. J Appl Sport Psychol 2001;13:40-59.

18 Udry E. Social support: exploring its role in the context of athletic injury. Journal of Sport Rehabilitation 1996:5:151-63.
19 Gilbourne D, Taylor AH. From theory to practice: the integration of goal perspective theory and life development approaches within an injury-specific goal-setting program. Journal of Applied Sport Psychology 1998; 10:124-39.

20 Granito VJ, Hogan JB, Varnum LK. The performance enhancement group: integrating sport psychology and rehabilitation. J Athl Train 1995:30:328-31.

21 levleva L, Orlick T. Mental links to enhanced healing: an exploratory study. Sport Psychology $1991 ; 5: 25-40$

\section{To treat or not to treat: new evidence for the effectiveness of manual therapy}

\section{M Sran}

Manual therapy has been shown to be effective for certain conditons but more research is needed to identify other suitable patients

$\mathrm{R}$ ecent randomised clinical trials found manual therapy to be more effective than other methods of conservative management for low back and neck pain. ${ }^{1-5}$ On the other hand, some randomised clinical trials, ${ }^{6-13}$ systematic reviews, ${ }^{14}$ and meta-analyses ${ }^{15}$ concluded that there was no evidence that spinal manipulative therapy is superior to other standard treatments for patients with low back or neck pain. This provides the clinician with a Shakespearean quandary-to treat or not to treat using manual therapies? Therefore this leader addresses the question: what explains these apparently inconsistent data?

\section{DEFINITIONS AND SEARCH STRATEGY}

The term manual therapy has many connotations, but for this leader it includes manually performed assessment and treatment methods (which can include joint, neural tissue, and/or muscle techniques). The term manipulation is typically used to describe small amplitude thrust techniques performed with speed. ${ }^{16}$

I searched Medline, Cinahl, and Embase databases for randomised clinical trials comparing spinal manual joint techniques (mobilisation with or without manipulation) or manipulation only with other conservative treatments for back or neck pain. Only studies published as full papers, in English, between 1 January 1998 and 31 December 2003 were included. Pilot studies were not included. Table 1 out-

Table 1 Search strategy
22 Lynch GP. Athletic injuries and the practicing sport psychologist: practical guidelines for assisting athletes. Sport Psychology 1988;2:161-7.

23 Smith AM. Psychological impact of injuries in athletes. Sports Med 1996;6:391-405.

24 Taylor J, Taylor S. Psychological approaches to sports injury rehabilitation. Gaithersburg, MD: Aspen Publications, 1997.

25 Horton AS, Bloom GA, Johnston KM. The impact of support groups on the psychological state of athletes experiencing concussions. Med Sci Sports Exerc 2002;34:99.

\section{DIFFERENCES IN MANUAL THERAPY THAT MAY EXPLAIN STUDY FINDINGS \\ Whether or not the study used manual therapy or manipulation only \\ Four of the 13 studies reported better} results in the manual therapy group than the other group(s). ${ }^{1-4}$ Five of the remaining nine studies used manipulation only, and all but one ${ }^{5}$ reported no significant difference or a poorer response than the other group $(\mathrm{s}) .^{781011}$

Use of a variety of manual therapy techniques, rather than joint manipulation alone, appears to yield better results. For example, Jull et al ${ }^{3}$ studied the effectiveness of manual therapy delivered by physical therapists, specific exercise therapy delivered by physical therapists, combined manual and specific exercise therapy, and a control group, for treatment of cervicogenic headache. At the 12 month follow up, both manual therapy and specific exercise groups had significantly reduced headache frequency and intensity, neck pain, and disability. In this study, ${ }^{3}$ manual therapy included both low velocity cervical joint mobilisation techniques and high velocity manipulation techniques. These results are relevant to physical therapists with postgraduate certification in manual therapy, as they are well trained in both of these techniques. Similarly, Hoving et $a l^{2}$

\begin{tabular}{lll}
\hline Database & MeSH headings & Limits \\
\hline Medline & Manipulation, orthopaedic & Human \\
& Manipulation, chiropractic & English \\
& Physical thion, osteopathic & $1998-2003$ \\
& Musculoskeletal manipulations & \\
& Comparative study & \\
& (Back or neck) and pain & \\
Cinahl & Manual therapy & English \\
& Chiropractic & Clinical trial \\
& Chiropractic manipulation & $1998-2003$ \\
& Manipulation, orthopaedic & \\
Osteopathy & \\
& (Back or neck) and pain & Human \\
& Manipulative medicine & English \\
& (Back or neck) and pain & $1998-2003$ \\
\hline
\end{tabular}




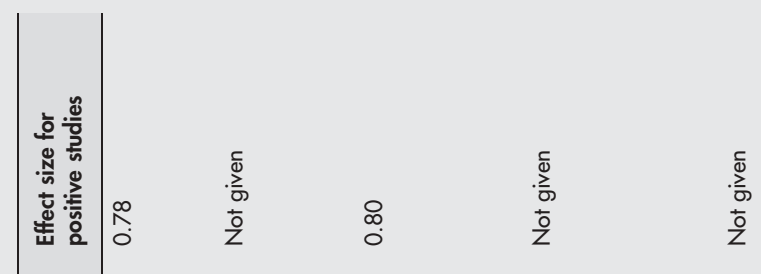

Mnd

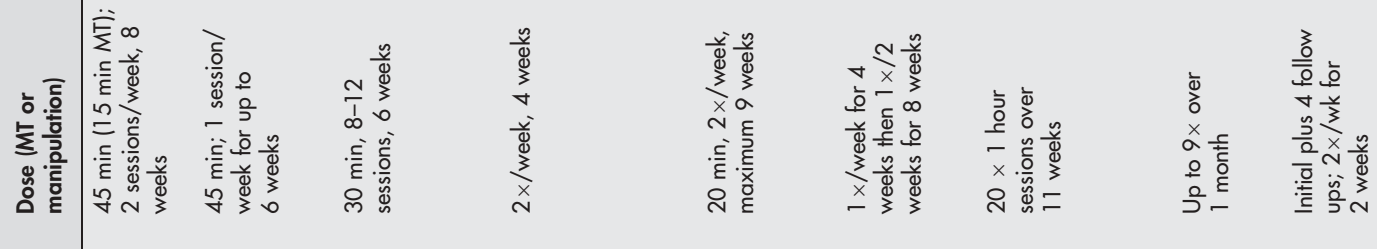

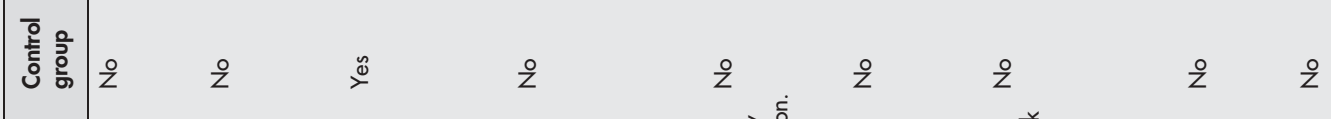

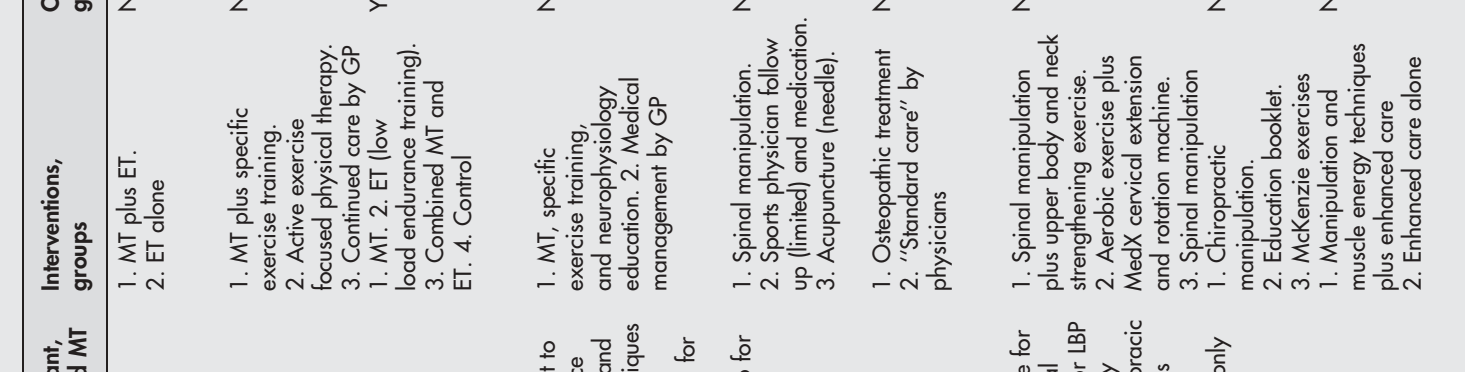

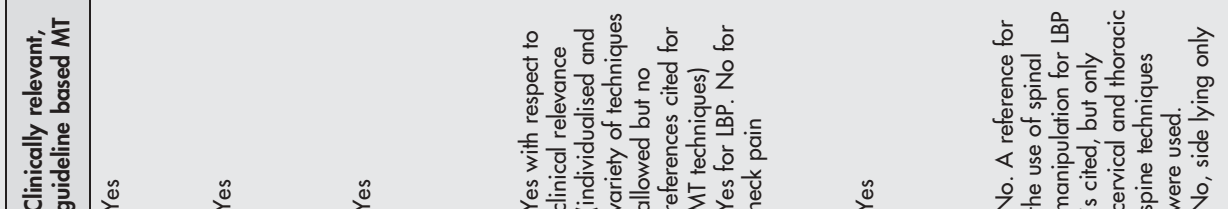

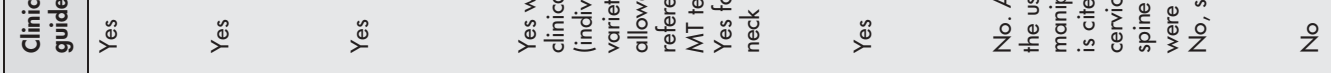

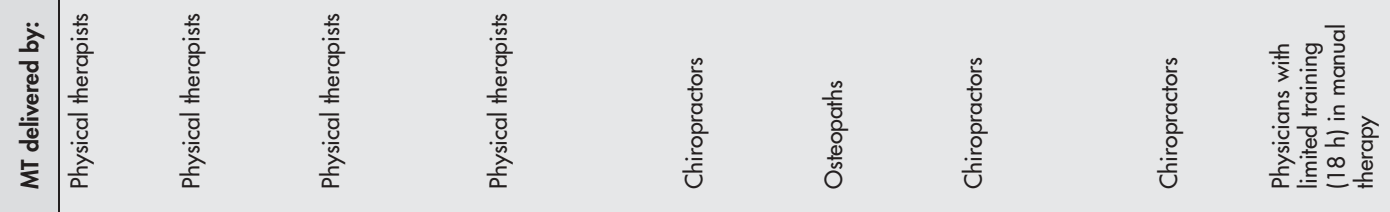

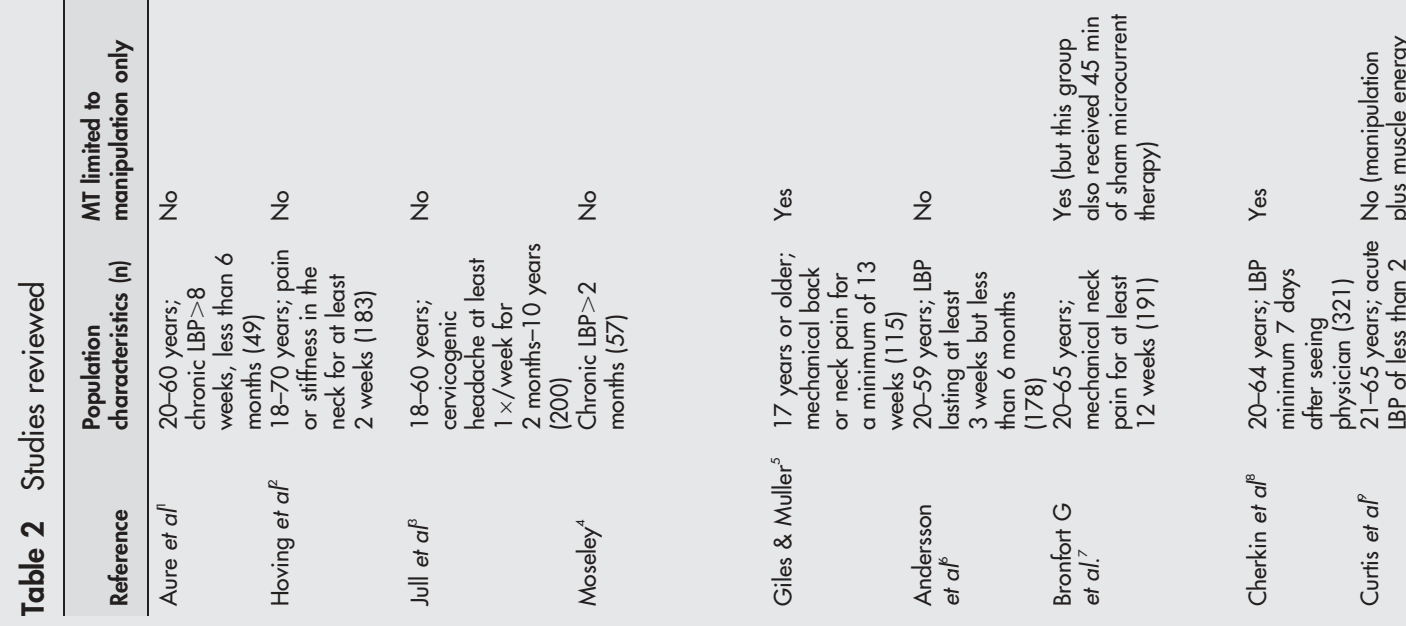




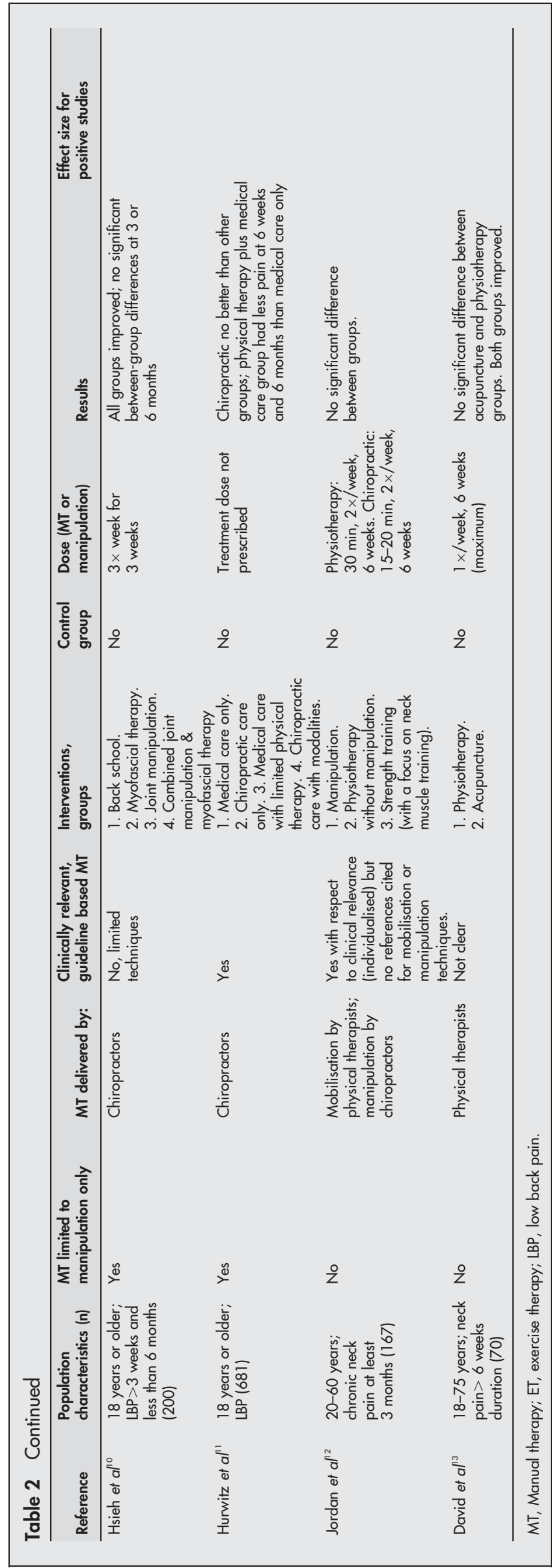

compared physical therapy including manual therapy with physical therapy without manual therapy for patients with chronic neck pain. Of note, they allowed the use of low velocity joint mobilisations but no high velocity low amplitude thrust techniques (synonymous with "manipulation").

\section{Was the choice of intervention \\ based on clinically relevant treatment guidelines ("best practice") of the discipline?}

Assessment and treatment protocols used in randomised controlled trials (RCTs) are not always similar to clinical practice guidelines, which are typically textbooks or guidelines written by experts in the field/discipline and based on current available evidence. Treatment protocols that do not mirror clinical practice have been examined in some studies. For example, Andersson et $a l^{6}$ compared osteopathic treatment (including manual therapy) with "standard care" by doctors. However, the reported standard care included medication, active physical therapy, ultrasonography, diathermy, hot or cold packs (or both), use of a corset, or transcutaneous electrical nerve stimulation (TENS). Clearly health maintenance organisation doctors do not have the time (45 minutes), equipment, or skillsthat is, active physical therapy-to provide this treatment. Further, two of the groups studying manipulation by chiropractors included participants with back or neck pain, yet they only cited references for low back pain management. ${ }^{57}$ Three studies used very restricted manual assessment and/or treatment techniques ${ }^{8-10}$ which do not reflect best practice. Three of the five studies with positive results used manual treatment (by physical therapists) based on published guidelines or clinical texts written by experts in the field..$^{1-3}$

\section{The dose of manual therapy or manipulation (minutes, sessions, weeks)}

The optimal dose is also a consideration. Time per session, number of sessions, and number of weeks are all important factors for therapists, patients, and payors.

Knowing the optimal treatment duration has obvious implications on cost effectiveness, but probably also has an impact on the effectiveness of manual therapy. Despite the importance of these variables, there is great variability between the protocols used in these 13 studies. One study compared chiropractic care only, medical care only, medical care with limited physical therapy, and chiropractic care with modalities but did not prescribe a treatment dose. ${ }^{11}$ 
However, they did monitor use of the various treatment modes and time per session and found that one third of patients randomly assigned to medical care with physical therapy had no physical therapy visits, and $20 \%$ of patients in the chiropractic groups received concurrent medical care, whereas only $7 \%$ of patients in the medical care groups received concurrent chiropractic care. They also report that chiropractors and medical providers in their study spent an average of 15 minutes with patients at each visit, and physical therapists averaged 31 minutes per patient visit.

Only six studies reported the time per session. Time varied from 20 to $60 \mathrm{~min}$ utes per treatment. Of interest, three of the five studies with positive results allowed between 30 and 45 minutes per treatment. One (of the studies with positive results) did not report treatment time, ${ }^{4}$ and the other had mixed results (positive for back pain but not for neck pain) and allowed 20 minutes per treatment. ${ }^{5}$

The total number of sessions varied from 5 to 20, with a frequency of between once a week and three times a week. Some studies did not prescribe a maximum or minimum number of sessions a week (table 2 ).

The number of weeks of treatment varied from 3 to 12 . Of note, the five studies with positive results used between four and nine weeks of treatment. ${ }^{1-5}$

\section{Combination therapies}

A number of studies have investigated a combination of therapies such as two healthcare professionals or a combination of manual therapy or manipulation with another mode of treatment.

Of note, four of the five studies with positive results used manual therapy in combination with another aspect of physical therapy (exercise therapy, ${ }^{12}$ specific exercise training, ${ }^{3}{ }^{4}$ and neurophysiology education ${ }^{4}$ ). Similar positive results were not seen in chiropractic studies of spinal manipulation combined with exercise ${ }^{710}$ or modalities. ${ }^{11}$

\section{METHODOLOGICAL FACTORS}

This critical appraisal also examined two key methodological factors that can influence randomised RCT findings. Firstly, the presence or absence of a control group is an important factor, yet only one ${ }^{3}$ study had a control (table 2 ). Secondly, an important issue when examining discordant outcomes of RCTs is power, ${ }^{18}$ as underpowered studies can lead to type II error. Fewer than one third of the studies reviewed reported prospective power calculations, ${ }^{1389}$ and one study reported what appears to be retrospective power. ${ }^{10}$
Retrospective power has limitations as described in detail elsewhere, ${ }^{19}$ thus all RCTs should calculate power a priori.

\section{SUMMARY AND CONCLUSIONS}

In summary, I return to the question that was the genesis of this leader, what explains the apparently inconsistent data in the field of manual therapy outcomes? Critical appraisal suggests that more precise interventions are successful in treating low back pain, chronic neck pain, and cervicogenic headache. There are clinically relevant differences between studies reporting positive results of manual therapy and those reporting no significant difference over other conservative treatments. Specifically, the treatment protocol needs to reflect what therapists are actually doing in clinical practice-that is, using more than one manual therapy technique or combining manual therapy with other modes of treatment such as specific exercise training. Interventions based on best practice guidelines/texts appear to be more successful, and physical therapy including manual therapy at a dose of 30-45 minutes per session, for four to eight weeks has been shown to be effective. ${ }^{1-4}$

Further research is needed to identify populations who are most likely to improve with manual therapy. For example, Flynn et al ${ }^{20}$ identified five variables to form a clinical prediction rule for patients with low back pain who are likely to respond favourably to a specific manipulative technique. In that study decisions on the side to be manipulated were not based on clinical best practice guidelines and only one manipulation technique was used (thus not representative of clinical practice), yet this approach to refine clinically relevant procedures may prove very useful.

Finally, manual therapy is not only used in the treatment of low back and neck pain. Further investigations of the effectiveness of manual therapy in special populations are needed. Pilot studies have been conducted in patients with thoracic pain, ${ }^{21}$ cervicobrachial pain syndrome, ${ }^{22}$ and we have conducted studies on the safety of manual therapy in the osteoporotic spine. ${ }^{23}$ The next step is for researchers to conduct well designed RCTs to determine the effectiveness of manual therapy for pain and disability in these populations.

\section{ACKNOWLEDGEMENTS}

I have received scholarships from the Vancouver Foundation (BCMSF), Michael Smith Foundation for Health Research (Doctoral Traineeship), and the Canadian Institutes of Health Research (Alberta Bone and Joint Health Training Program).
Br J Sports Med 2004;38:521-525. doi: 10.1136/bjsm.2003.010876

Correspondence to: M M Sran, Division of Orthopaedic Engineering Research, Department of Orthopaedics, Faculty of Medicine, University of British Columbia, VGH Research Pavilion, Room 500, 828 W 10th Ave, Vancouver, BC V5Z 1 L8 Canada; mmsran@interchange.ubc.ca

\section{REFERENCES}

1 Aure OF, Nilsen JH, Vasselien O. Manua therapy and exercise therapy in patients with chronic low back pain: a randomized, controlled trial with 1-year follow-up. Spine 2003;28:525-31.

2 Hoving JL, Koes BW, de Vet HC, et al. Manual therapy, physical therapy, or continued care by a general practitioner for patients with neck pain. A randomized, controlled trial. Ann Intern Med 2002; 136:713-22.

3 Jull G, Trott $\mathrm{P}$, Potter $\mathrm{H}$, et al. A randomized controlled trial of exercise and manipulative therapy for cervicogenic headache. Spine 2002;27: 1835-43.

4 Moseley L. Combined physiotherapy and education is efficacious for chronic low back pain. Aust J Physiother 2002;48:297-302.

5 Giles LG, Muller R. Chronic spinal pain: a randomized clinical trial comparing medication, acupuncture, and spinal manipulation. Spine 2003;28: 1490-502.

6 Andersson GB, Lucente T, Davis AM, et al. A comparison of osteopathic spinal manipulation with standard care for patients with low back pain. N Engl J Med 1999;341:1426-31.

7 Bronfort G, Evans R, Nelson B, et al. A randomized clinical trial of exercise and spinal manipulation for patients with chronic neck pain. Spine $2001 ; 26: 788-97$.

8 Cherkin DC, Deyo RA, Battie M, et al. A comparison of physical therapy, chiropractic manipulation, and provision of an educational booklet for the treatment of patients with low back pain. N Engl J Med 1998;339:1021-9.

9 Curtis P, Carey TS, Evans P, et al. Training primary care physicians to give limited manual therapy for low back pain: patient outcomes. Spine 2000;25:2954-60.

10 Hsieh CY, Adams AH, Tobis J, et al. Effectiveness of four conservative treatments for subacute low back pain: a randomized clinical trial. Spine 2002;27:1142-8.

11 Hurwitz EL, Morgenstern H, Harber P, et al. A randomized trial of medical care with and without physical therapy and chiropractic care with and without physical modalities for patients with low back pain: 6-month follow-up outcomes from the UCLA low back pain study. Spine 2002; 27:2193-204.

12 Jordan A, Bendix T, Nielsen H, et al. Intensive training, physiotherapy, or manipulation for patients with chronic neck pain. A prospective, single-blinded, randomized clinical trial. Spine 1998:23:311-18.

13 David J, Modi S, Aluko AA, et al. Chronic neck pain: a comparison of acupuncture treatment and physiotherapy. Br J Rheumatol 1998;37:1118-22.

14 Gross AR, Kay T, Hondras M, et al. Manual therapy for mechanical neck disorders: a systematic review. Man The 2002; 7:131-49.

15 Assendelft WJ, Morton SC, Yu El, et al. Spinal manipulative therapy for low back pain. A meta-analysis of effectiveness relative to other therapies. Ann Intern Med 2003;138:871-81

16 Maitland GD, Banks K, English K, et al. Maitland's vertebral manipulation, 6th ed. Boston: Butterworth Heinemann, 2001

17 Hemmila HM, Keinanen-Kiukaanniemi SM Levoska S, et al. Long-term effectiveness of bonesetting, light exercise therapy, and physiotherapy for prolonged back pain: a randomized controlled trial. J Manipulative Physiol Ther 2002;25:99-104. 
18 Glantz SA. Primer of biostatistics, 5th ed. New York: McGraw-Hill, 2001.

19 Zumbo B, Hubley A. A note on misconceptions concerning prospective and restrospective power. The Statistician 1998;47: 385-8.

20 Flynn T, Fritz J, Whitman J, et al. A clinical prediction rule for classifying patients with low back pain who demonstrate short-term improvement with spinal manipulation. Spine 2002;27:2835-43.

21 Schiller L. Effectiveness of spinal manipulative therapy in the treatment of mechanical thoracic spine pain: a pilot randomized clinical trial $J$ Manipulative Physiol Ther 2001;24:394-401.
22 Allison GT, Nagy BM, Hall T. A randomized clinical trial of manual therapy for cervicobrachial pain syndrome: a pilot study. Man Ther 2002;7:95-102.

23 Sran MM, Khan KM, Zhu Q, et al. Failure characteristics of the thoracic spine with a posteroanterior load: investigating the safety of spinal mobilization. Spine 2004;24:in press.

\section{ELECTRONIC PAGES}

\section{BJSM Online case reports: http://bjsm.bmijournals.com/}

?

he following electronic only articles are published in conjunction with this issue of BJSM.

\section{Aseptic bone necrosis in an amateur scuba diver} G D M Laden, P Grout

A case is reported that provides further evidence of an old occupational hazard, dysbaric osteonecrosis, presenting in a new population (sports scuba divers) who also appear to be at risk. It highlights the need for an accurate diagnosis of diving related illness.

(Br J Sports Med 2004;38:e19) http://bjsm.bmjjournals.com/ cgi/content/full/38/5/e19

\section{Abdominal coarctation in a hypertensive female collegiate basketball player}

B Sloan, S Simons, A Stromwall

The purpose of the preparticipation examination is to identify health conditions that might adversely affect an athlete while participating in sport. Hypertension is the most common. This case report details a female basketball player found to be hypertensive, and complaining of fatigue, at her preparticipation physical examination. Presentation, diagnostics, treatment, and final outcome of coarctation involving the abdominal aorta are summarised.
(Br J Sports Med 2004;38:e20) http://bjsm.bmjjournals.com/ cgi/content/full/38/5/e20

Clinical and magnetic resonance imaging features of cricket bowler's side strain

D Humphries, M Jamison

The clinical features of 10 cases of lateral trunk muscle injury in first class cricket pace bowlers are described. Typically the injury occurs during a single delivery, is associated with considerable pain, and prevents the bowler from continuing.

The clinical picture is typical of a muscular or musculotendinous injury. The most consistent clinical tests were focal tenderness on palpation and pain with resisted side flexion towards the painful side. The magnetic resonance image in.

$70 \%$ of cases was consistent with an injury to the internal oblique, the external oblique, or the transversalis muscles at or near their attachments to one or more of the lowest four ribs. The injury occurs on the non-bowling arm side. Recovery can be prolonged. The injury was a recurrence in six of the 10 cases. The biomechanics of the injury are not yet understood.

(Br J Sports Med 2004;38:e21) http://bjsm.bmjjournals.com/ cgi/content/full/38/5/e21 


\section{PostScript}

\section{LETTER}

If you have a burning desire to respond to a paper published in Br J Sports Med, why not make use of our "rapid response" option?

Log on to our website (www.bjsportmed. com), find the paper that interests you, click on "full text" and send your response by email by clicking on "eletters" submit a response.

Providing it isn't libellous or obscene, it will be posted within seven days. You can retrieve it by clicking on "read eletters" on our homepage.

\section{Sodium ingestion and the prevention of hyponatraemia during exercise}

The study of Twerenbold et $a l^{1}$ is important for a number of reasons, not all of which may have been emphasised sufficiently by the authors.

Firstly, it confirms that a rate of fluid intake of $1000 \mathrm{ml} / \mathrm{h}$ is too high for a group of female runners running at $\sim 10 \mathrm{~km} / \mathrm{h}$ and who would therefore complete a $42 \mathrm{~km}$ marathon in about 4.25 hours. As the athletes drank 4 litres and gained $2 \mathrm{~kg}$ during the trial, their average rate of weight loss (as opposed to sweat rate) was about $500 \mathrm{ml} / \mathrm{h}$. As not all of the weight lost during exercise is sweat and as much as $1-3 \mathrm{~kg}$ of this weight loss may result from fuel and water losses that do not contribute to dehydration, ${ }^{23}$ the absolute maximum rate at which these athletes should have ingested fluid during exercise was probably even less than $500 \mathrm{ml} / \mathrm{h}$. This is substantially less than the drinking guidelines of the American College of Sports Medicine $^{45}$ and the Gatorade Sports Science Institute, ${ }^{6}$ which have promoted rates of fluid ingestion of up to $1200-1800 \mathrm{ml} / \mathrm{h}$. As there is no evidence that gaining weight during exercise improves performance ${ }^{78}$ whereas there is good evidence that athletes who either lose no weight or who gain weight during exercise are increasingly likely to $(a)$ have an impaired performance, ${ }^{7}(b)$ develop troubling gastrointestinal symptoms, ${ }^{7-10}$ or $(c)$ finish the race with serum sodium concentrations below about $128 \mathrm{mmol} / \mathrm{l}$ causing hyponatraemic encephalopathy, ${ }^{11-13}$ it is not immediately clear why the authors chose such high rates of fluid intake in these athletes. Except, perhaps, if they wished to "prove" the value of sodium ingestion during exercise. I note, for example, that the study was funded by a commercial company that, I am informed, markets a sports drink containing sodium chloride.

For it seems highly probable that if athletes overdrink so that they retain fluid and gain weight, then the extent to which their serum sodium concentration falls will be influenced, albeit to a quite limited extent, by the sodium content of the ingested fluids. This indeed was shown by the results of this study. But whether that finding has relevance to the sodium requirements of athletes who are specifically advised not to overdrink during exercise to ensure that they do not develop hyponatraemic encephalopathy ${ }^{13}$ is an entirely different question, which cannot be answered with the study design chosen by these authors.

For example, the presence of a control group who drank according to the dictates of thirst ("ad libitum") and not according to the guidelines of influential sports medical ${ }^{45}$ and

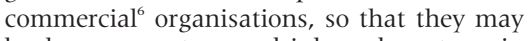
be less prone to overdrink and so to gain weight during exercise, would have established that athletes who lose more than 1-3 kg during exercise do not develop symptomatic hyponatraemic encephalopathy ${ }^{11-16}$ even though they are both dehydrated and sodium deficient. Rather, they are more likely to finish such races with raised serum sodium concentrations. ${ }^{12-16}$

I would rather argue that a fundamental feature of all prospective trials that aim to evaluate a novel intervention such as the role of sodium ingestion in the prevention of hyponatraemia during exercise should be to compare the new intervention with the currently established "best practice".

As the currently established best practice is not to ingest fluid at such high rates that weight is gained during exercise, because this practice can produce a fatal outcome, ${ }^{17}$ so this study design should, in retrospect, not have been sanctioned. Rather, the control group in the study should have ingested fluid according to guidelines based on the strongest body of current information. It is, for obvious reasons, my biased opinion that the guidelines that come closest to a defendable evidence base are those that have been recently accepted by the United States Track and Field and the International Marathon Medical Directors Association. ${ }^{16}$

Fortunately the data of Twerenbold et al ${ }^{1}$ do allow some calculations to estimate the likely value of the extra sodium that was ingested by two of their groups. Thus, the athletes in their study had a mean weight of $58 \mathrm{~kg}$. According to the formula of Montain et al, ${ }^{18}$ their predicted extracellular fluid (ECF) volume would be about 14.5 litres $(25 \%$ of body weight). As the starting serum (and ECF) sodium concentration $\left(\left[\mathrm{Na}^{+}\right]\right)$in the three groups of runners was $\sim 137 \mathrm{mmol} / \mathrm{l}$ (table 3 of their article ${ }^{1}$ ), the average total ECF $\mathrm{Na}^{+}$content of the three experimental groups was 1989-1993 mmol at the start of the race. As weights increased by $1.8-2.1 \mathrm{~kg}$ in the three groups during exercise (table 3 of their article ${ }^{1}$ ), the increases in ECF volume would have been $450-525 \mathrm{ml}$ in the respective groups, assuming that the ECF increased in proportion to the increase in total body water (TBW). Multiplying this new ECF volume by the serum $\left[\mathrm{Na}^{+}\right]$after the race gives the new total ECF $\mathrm{Na}^{+}$content after the race. As shown in table 1 , the total ECF $\mathrm{Na}^{+}$ content increased by $34 \mathrm{mmol}$ in the group that ingested the high salt drink $(\mathrm{H})$ during the race, but fell by $23 \mathrm{mmol}$ in the group drinking water (W). As all groups ran for about four hours, according to these calculations and based on these assumptions, the hourly rates of $\mathrm{Na}^{+}$loss would have varied from 6 to $21 \mathrm{mmol} / \mathrm{h}$, giving a sweat $\left[\mathrm{Na}^{+}\right]$of $12-42 \mathrm{mmol} / \mathrm{l}$ in the $\mathrm{W}$ and $\mathrm{H}$ groups respectively (as their total sweat losses were $\sim 2$ litres in each group).

The clear paradox identified by the calculations in table 1 is that $(a)$ the total $\mathrm{Na}^{+}$loss apparently increases with increased $\mathrm{Na}^{+}$ intake and $(b)$ the estimated $\mathrm{Na}^{+}$loss in the group who ingested only water during the race $(\mathrm{W})$ is less than one third of that in the group who ingested the most $\mathrm{Na}^{+}(\mathrm{H})$ during the race.

As these calculations are based on two real measurements (body weight changes and changes in plasma $\left.\left[\mathrm{Na}^{+}\right]\right)$, this apparently ludicrous conclusion can only be explained if (a) $\mathrm{Na}^{+}$ingestion during exercise increases whole body $\mathrm{Na}^{+}$losses in sweat and urine or (b) the estimated ECF volume in the W group after exercise is less than the value calculated. That is, specifically in the $\mathrm{W}$ group, the ECF volume contracted despite an increase in TBW of 1.9 litres. Indeed, this response is to be expected. There is consistent evidence that the response of the ECF and the intracellular fluid (ICF) volumes to fluid ingestion during prolonged exercise are influenced by the $\mathrm{Na}^{+}$ content of the ingested fluid ${ }^{19-21}$ so that the plasma volume is likely to fall the most if no fluid is ingested, ${ }^{19}$ to fall less if either water ${ }^{19}$ or a dilute $\mathrm{Na}^{+}$drink is ingested, ${ }^{19-21}$ or to expand if a concentrated (50-100 mmol/l) $\mathrm{Na}^{+}$drink is ingested at the same rate that body weight is lost during exercise. ${ }^{20}$ In the latter case, any reduction in the TBW appears to come from a reduction in the ICF. ${ }^{20}$

For example, if each group did indeed lose $84 \mathrm{mmol} \mathrm{Na}^{+}$as did group $\mathrm{H}$ (table $\mathrm{l}$ ), a value that seems eminently reasonable as it equates to a quite reasonable sweat $\left[\mathrm{Na}^{+}\right]$of $\sim 40 \mathrm{mmol} / \mathrm{l},{ }^{22}$ then the true ECF volume in the $\mathrm{W}$ group after the race would have been 14.5 litres-that is, it is unchanged from the starting value. This value (expressed in litres) is calculated as: (pre-race ECF $\mathrm{Na}^{+}$content 84 ) in mmol divided by post-race serum $\left[\mathrm{Na}^{+}\right]$in $\mathrm{mmol} / \mathrm{l}$.

Indeed, if subjects in the $\mathrm{W}$ group did lose $84 \mathrm{mmol} \mathrm{Na}^{+}$during the race but also had a post-race ECF volume expanded to 14.95 litres, then their post-race $\left[\mathrm{Na}^{+}\right]$would have been even lower $(128 \mathrm{mmol} / \mathrm{l})$ than that actually measured after the race $(132 \mathrm{mmol} / \mathrm{l}$; table 1). It is probable that, at that low serum $\left[\mathrm{Na}^{+}\right]$, they would have exhibited the early symptoms of hyponatraemic encephalopathy. ${ }^{11}$ That they did not have such low serum $\left[\mathrm{Na}^{+}\right]$indicates the importance of small changes in ECF volume (in this case only $450 \mathrm{ml}$ or $\sim 3 \%$ of the total ECF volume) in determining the extent to which the serum $\left[\mathrm{Na}^{+}\right]$changes during prolonged exercise in which subjects both sweat and ingest fluid to excess. ${ }^{11}$

Unfortunately, the vital importance of these small changes in ECF volume in determining whether hyponatraemic encephalopathy will develop in those who overdrink during exercise ${ }^{11}$ continues fastidiously to be ignored by those $e^{1-61823-25}$ who argue incorrectly that it is the $\mathrm{Na}^{+}$deficit that determines the extent to which the serum $\left[\mathrm{Na}^{+}\right]$ falls in those who develop hyponatraemia during exercise. This calculation elegantly shows why small changes in ECF volume determine whether or not hyponatraemic 
Table 1 Sodium balance calculations for three groups of runners running at $\sim 10 \mathrm{~km} / \mathrm{h}$ for four hours while ingesting solutions with different $\left[\mathrm{Na}^{+}\right]$

\begin{tabular}{|c|c|c|c|c|c|c|c|c|c|}
\hline & $\begin{array}{l}\text { Pre-race } \\
{\left[\mathrm{Na}^{+}\right]} \\
(\mathrm{mmol} / \mathrm{l})(\mathrm{A})\end{array}$ & $\begin{array}{l}\text { Pre-race } \\
\text { ECF volume } \\
\text { (litres) (B) }\end{array}$ & $\begin{array}{l}\text { Pre-race ECF } \\
\mathrm{Na}^{+} \text {content } \\
(\mathrm{mmol})(\mathrm{A} \times \mathrm{B})\end{array}$ & $\begin{array}{l}\text { Post-race }\left[\mathrm{Na}^{+}\right] \\
(\mathrm{mmol} / \mathrm{I})(\mathrm{C})\end{array}$ & $\begin{array}{l}\text { Post-race } \\
\text { ECF volume } \\
\text { (litres) (D) }\end{array}$ & $\begin{array}{l}\text { Post-race ECF } \\
\mathrm{Na}^{+} \text {content } \\
(\mathrm{mmol})(\mathrm{C} \times \mathrm{D})\end{array}$ & $\begin{array}{l}\text { Post-race } \mathrm{Na}^{+} \\
\text {balance }(\mathrm{mmol})(\mathrm{E}) \\
(\mathrm{C} \times \mathrm{D})-(\mathrm{A} \times \mathrm{B})\end{array}$ & $\begin{array}{l}\text { Amount of } \\
\mathrm{Na}^{+} \text {ingested } \\
(\mathrm{mmol}) \text { (F) }\end{array}$ & $\begin{array}{l}\text { Apparent amount } \\
(\mathrm{mmol}) / \text { rate } \\
\text { of } \mathrm{Na}^{+} \text {loss during } \\
\text { exercise (mmol/h) } \\
((\mathrm{F}-\mathrm{E}) / \mathrm{L})\end{array}$ \\
\hline $\mathrm{H}$ & 137.3 & $14.50^{*}$ & 1991 & 134.8 & 15.02 & 2025 & +34 & $118 \dagger$ & $84 / 21$ \\
\hline L & 137.2 & 14.50 & 1989 & 132.8 & 14.95 & 1985 & -4 & 71 & $76 / 19$ \\
\hline W & 137.5 & 14.50 & 1993 & 131.8 & 14.95 & 1970 & -23 & 0 & $24 / 6$ \\
\hline
\end{tabular}

$\mathrm{H}$, High sodium intake; $\mathrm{L}$, low sodium intake; $\mathrm{W}$, water during exercise.

*Based on $25 \%$ of mean body weight of $57.7 \mathrm{~kg}$ for the total group of runners. Weights for different groups were not reported.

†From table 2 of Twerenbold et al': to convert $\mathrm{mg}$ sodium (table 2) into mmol sodium, divide by the molecular weight of sodium (22.99).

encephalopathy will develop in those who overdrink, regardless of whether or not they also incur a $\mathrm{Na}^{+}$deficit either during exercise $^{311-13152627}$ or at rest. ${ }^{229}$ A recent paper ${ }^{30}$ confirms these predictions by showing that mathematical modelling supports the argument that changes in TBW exert a much greater effect on serum $\left[\mathrm{Na}^{+}\right]$than does whole body $\mathrm{Na}^{+}$content in those who overdrink and hence gain weight during exercise.

Perhaps the point of these calculations is to show that it is not possible to calculate the state of $\mathrm{Na}^{+}$balance in athletes during exercise and so to determine whether or not athletes have developed a $\mathrm{Na}^{+}$"deficit", ${ }^{1623-25}$ simply by measuring serum $\left[\mathrm{Na}^{+}\right]$. This is because the ECF volume will not be the same before, during, and after exercise and will change depending on the nature of the fluid ingested and the extent of any fluid deficit or excess that develops during exercise..$^{19-21}$

But more importantly, these calculations clearly show why the regulation of the TBW and the ECF volume will have a much greater influence on serum $\left[\mathrm{Na}^{+}\right]$than will either the expected $\mathrm{Na}^{+}$losses in sweat or the amount of $\mathrm{Na}^{+}$ingested from sodium-containing sports drinks. ${ }^{11}{ }^{30}$

For example a 1 litre $(7 \%)$ reduction in the ECF volume would "release" $140 \mathrm{mmol} \mathrm{Na}{ }^{+}$ into the contracted ECF volume. This means that it is possible to lose $140 \mathrm{mmol} \mathrm{Na}{ }^{+}$in sweat and urine without any change in serum $\left[\mathrm{Na}^{+}\right]$provided that the ECF volume were to contract by only $7 \%$. If sweat $\left[\mathrm{Na}^{+}\right]$is about $40 \mathrm{mmol} / \mathrm{l}$, as appears to have been the case in this study of Twerenbold et al (table 1), then this $140 \mathrm{mmol}$ is the equivalent of the $\mathrm{Na}^{+}$content of about 3.5 litres of sweat.

As athletes in this study sweated at a maximum rate of only $500 \mathrm{ml} / \mathrm{h}$ when running at $10 \mathrm{~km} / \mathrm{h}$, this means that simply by reducing their ECF volume by 1 litre, those athletes could have maintained their pre-race serum $\left[\mathrm{Na}^{+}\right]$while running for seven hours and drinking just sufficient water to allow for a 1 litre reduction in ECF volume and without requiring any $\mathrm{Na}^{+}$replacement whatsoever. This simple calculation explains why those endurances athletes who, before about 1969, were advised either not to drink at all, or only sparingly during exercise, ${ }^{31}$ always finished their races with raised serum $\left[\mathrm{Na}^{+}\right]^{32-39}$ despite having incurred what might have been quite sizeable $\mathrm{Na}^{+}$deficits.

In contrast, athletes in this study who believed the incorrect advice that ingesting $\mathrm{Na}^{+}$and fluid at high rates is essential to maintain a normal serum $\left[\mathrm{Na}^{+}\right]$during exercise, ${ }^{4-61823-25}$ so they overdrank sufficiently to increase their ECF volume by
1 litre, would need to ingest and retain at least an additional $140 \mathrm{mmol} \mathrm{Na}^{+}$in addition to the $\sim 80 \mathrm{mmol}$ lost in sweat (table 1). This is equivalent to the $\mathrm{Na}^{+}$content of 12.4 litres of the low and 7.5 litres of the high sodium drinks respectively in this trial. To maintain fluid balance in this four hour trial when drinking at those high rates and sweating at about $500 \mathrm{ml} / \mathrm{h}$, they would then need to urinate at rates of $1375-2600 \mathrm{ml} / \mathrm{h}$. Both of these rates exceed the maximum at which human kidneys are able to produce urine at rest, ${ }^{28} 29$ let alone during and after prolonged exercise. ${ }^{11}{ }^{13}$ Drinking at such rates would therefore only lead to progressive fluid accumulation and ultimately death from hyponatraemic encephalopathy. ${ }^{17}$

In summary, these calculations explain (a) why contraction of the ECF in athletes who lose body weight during exercise will maintain the serum $\left[\mathrm{Na}^{+}\right]$even in the face of quite large and unreplaced $\mathrm{Na}^{+}$loss in sweat, and (b) why the ingestion of sodium-containing sports drinks in the vain hope of matching the rates of $\mathrm{Na}^{+}$loss in sweat can only lead to fluid retention and progressive hyponatraemia, as elegantly shown by this study.' Indeed if this inappropriate behaviour is approached with sufficient vigour, ultimately the result will be death from hyponatraemic encephalopathy, ${ }^{17}$ which, as these calculations and this study again show, cannot occur without the presence of distinct fluid overload. ${ }^{11}$

Finally, it is important to note that, even though $\mathrm{Na}^{+}$ingestion marginally increased serum $\left[\mathrm{Na}^{+}\right]$in the group that ingested the most concentrated $\mathrm{Na}^{+}$drink, this practice was without benefit as running performances were unaltered by $\mathrm{Na}^{+}$ingestion, and the incidence of symptoms was no different between the groups as no athletes reportedly developed symptoms. However, the symptoms of mild hyponatraemic encephalopathy are mild and may not have been sought with sufficient diligence. For example, all subjects, myself included, in our study in which mild hyponatraemia was induced by fluid overload at rest, ${ }^{28}$ developed quite disabling symptoms at serum $\left[\mathrm{Na}^{+}\right]$of $\sim 136 \mathrm{mmol} / \mathrm{l}$ or lower. Indeed it would have been most interesting to determine whether the presence of subtle mental symptoms was different in the three groups in this study, as all had similar degrees of fluid overload despite different serum $\left[\mathrm{Na}^{+}\right]$. If the symptoms in this condition are due purely to fluid overload, then the incidence of symptoms should have been the same in all groups despite different serum $\left[\mathrm{Na}^{+}\right]$. Alternatively, if the symptoms are related to the degree of hyponatraemia, then they should have been most obvious in the $\mathrm{W}$ group, who finished with the lowest postrace serum $\left[\mathrm{Na}^{+}\right]$. My bias would be to expect that the extent of any symptoms are more likely related to the degree of fluid overload, and hence the increase in the ICF, than to the level to which the serum $\left[\mathrm{Na}^{+}\right]$has been reduced.

T Noakes

Correspondence to: University of Cape Town, Research Unit for Exercise Science and Sports Medicine, Sports Science of South Africa, PO Box

115, Newlands 7725, South Africa; tdnoakes@ sports.uct.ac.za

doi: 10.1136/bjsm.2004.014191

Conflict of interest: none declared

\section{References}

1 Twerenbold R, Knechtle B, Kakebeeke TH, et al. Effects of different sodium concentrations in replacement fluids during prolonged exercise in women. Br J Sports Med 2003;37:300-3

2 Pastene J, Germain M, Allevard AM, et al. Water balance during and after marathon running. Eur J Appl Physiol Occup Physiol 1996;73:49-55

3 Speedy DB, Noakes TD, Kimber NE, et al. Fluid balance during and after an ironman triathlon. Clin J Sport Med 2001;11:44-50.

4 Convertino VA, Armstrong LE, Coyle EF, et al. American College of Sports Medicine position stand. Exercise and fluid replacement. Med Sci Sports Exerc 1996;28:i-vii.

5 Armstrong LE, Epstein YE, Greenleaf JE, et al. Position stand: heat and cold illnesses during distance running. Med Sci Sports Exerc 1996;28:i-x

6 Murray B. How often should you drink fluids? Gatorade Sports Science Institute Sports Science Centre. 2002. http://www.gssiweb.com/reflib/ refs/419/200104_q1.cfm?pid = 38 .

7 Robinson TA, Hawley JA, Palmer GS, et al. Water ingestion does not improve 1-h cycling performance in moderate ambient temperatures Eur J Appl Physiol Occup Physiol 1995;71:153-60.

8 Noakes TD. Letter to the Editor. Int J Sport Nutr Exerc Metab 2004; 14:249-54.

9 Glace B, Murphy C, McHugh M. Food and fluid intake and disturbances in gastrointestinal and mental function during an ultramarathon. Int J Sport Nutr Exerc Metab 2002:12:414-27.

10 Glace BW, Murphy CA, McHugh MP. Food intake and electrolyte status of ultramarathoners competing in extreme heat. $J \mathrm{Am}$ Coll Nutr 2002;21:553-9.

11 Noakes T. Hyponatremia in distance runners: fluid and sodium balance during exercise. Curr Sports Med Rep 2002;1:197-207.

12 Speedy DB, Noakes TD, Rogers IR, et al. Hyponatremia in ultradistance triathletes. Med Sci Sports Exerc 1999:31:809-15.

13 Noakes TD, Sharwood K, Collins M, et al. The dipsomania of great distance. Water intoxication 
in an Ironman triathlete $\mathrm{Br} J$ Sports Med 2004;38:el6.

14 Sharwood K, Collins M, Goedecke J, et al. Weight changes, medical complications and performance during an Ironman triathlon. Br J Sports Med 2004; in press.

15 Speedy DB, Rogers IR, Noakes TD, et al. Diagnosis and prevention of hyponatremia at an ultradistance triathlon. Clin J Sport Med $2000 \cdot 10 \cdot 52-8$

16 Noakes TD. Fluid Replacement during Marathon Running. Clin J Sport Med 2003;13:309-18.

17 Noakes TD. Overconsumption of fluids by athletes. BMJ 2003;327:113-14.

18 Montain SJ, Sawka MN, Wenger CB. Hyponatremia associated with exercise: risk factors and pathogenesis. Exerc Sport Sci Rev 2001;29:113-17.

19 Sanders B, Noakes TD, Dennis SC. Water and electrolyte shifts with partial fluid replacement during exercise. Eur $J$ Appl Physiol Occup Physiol 1999;80:318-23.

20 Sanders B, Noakes TD, Dennis SC. Sodium replacement and fluid shifts during prolonged exercise in humans. Eur J Appl Physiol 2001;84:419-25.

21 Speedy DB, Thompson JM, Rodgers I, et al. Oral salt supplementation during ultradistance exercise. Clin J Sport Med 2002;12:279-84

22 Shirreffs SM, Maughan RJ. Whole body sweat collection in humans: an improved method with preliminary data on electrolyte content. $J$ Appl Physiol 1997:82:336-41.

23 Armstrong LE. Exertional hyponatremia. In: Armstrong LE, ed. Exertional heat illnesses. Champaign, IL: Human Kinetics Publishers, 2003:103-35.

24 Murray B, Eichner ER. Hyponatremia of exercise. Curr Sports Med Rep 2004;3:117-18.

25 Murray B, Stofan J, Eichner ER. "Water intoxication" and subsequent death has become a "hot" topic. How dangerous is it? Marathon \& Beyond 2004 Jan/Feb:77-92.

26 Irving RA, Noakes TD, Buck R, et al. Evaluation of renal function and fluid homeostasis during recovery from exercise-induced hyponatremia. J Appl Physiol 1991;70:342-8.

27 Speedy DB, Rogers IR, Noakes TD, et al. Exercise-induced hyponatremia is caused by inappropriate fluid retention. Clin J Sport Med 2000;10:272-8.

28 Noakes TD, Wilson G, Gray DA, et al. Peak rates of diuresis in healthy humans during oral fluid overload. S Afr Med J 2001;91:852-7.

29 Speedy DB, Noakes TD, Boswell T, et al Response to a fluid load in athletes with a history of exercise induced hyponatremia. Med Sci Sports Exerc 2001;33:1434-42.

30 Weschler LB. Exercise-associated hyponatremia: sensitivity of plasma $\mathrm{Na}^{+}$concentration to total body water, change in total body water and sum of exchangeable $\mathrm{Na}^{+}$and $\mathrm{K}^{+}$. Sports Med 2004; in press.

31 Noakes TD. Fluid replacement during exercise Exerc Sport Sci Rev 1993;21:297-330.

32 Beckner GL, Winsor T. Cardiovascular adaptations to prolonged effort. Circulation 1954;9:835-46

33 Pugh LGCE, Corbett JL, Johnson RH. Rectal temperatures, weight losses, and sweat rates in marathon running. J Appl Physio 1967;23:347-52.

34 Muir AL, Percy-Robb IW, Davidson IA, et al. Physiological aspects of the Edinburgh Commonwealth Games. Lancet 1970;2:1125-8.

35 Rose LI, Carroll DR, Lowe SL, et al. Serum electrolyte changes after marathon running. J Appl Physiol 1970;29:449-51.

36 Kavanagh T, Shephard RJ. Marathon running after myocardial infarction. JAMA 1974;229:1602-5.

37 Riley WJ, Pyke FS, Roberts AD, et al. The effects of long-distance running on some biochemical variables. Clin Chim Acta 1975;65:83-9

38 Noakes TD, Carter JW. Biochemical parameters in athletes before and after having run $160 \mathrm{~km}$. S Afr Med J 1976;50:1562-6.

39 McKechnie JK, Leary WP, Noakes TD. Metabolic responses to a $90 \mathrm{~km}$ running race. S Afr Med J 1982;61:482-4.

\section{BOOK REVIEWS}

\section{Tennis}

Edited by P A F H Renstrom. London: Blackwell Publishing, 2002, £29.95, pp 318, softcover. ISBN 0632050349

It is widely recognised that each sport has its own unique demands and injuries. Therefore the IOC, ITF, ATP, WTA, and Society for Tennis Medicine and Science should be congratulated on producing, in this publication, a comprehensive overview of tennis sports medicine. Together they have assembled an impressive array of experts in this field to write succinct and relevant chapters.

Every aspect of tennis is covered to cater for a broad range of readers, including players themselves. Some areas are covered in a high level of technical detail to please the biomechanists, in particular. However, some of the sports medicine is basic in concept and lacking significant evidence based validity.

Nevertheless, I would highly recommend this book to any health professional who treats a large number of tennis players. Most chapters provide a clever link between common sports medicine problems and their occurrence in tennis, including conditions that are unique to this sport. At times, some authors are somewhat optimistic with their view of recovery time from surgery-for example, three weeks for arthroscopic debridement of the infrapatellar fat pad.

Overall it is well presented with relevant and useful photographs and diagrams to aid the reader, and each chapter gives a list of further recommended reading. Unfortunately the book does not provide an answer to where 14 million tennis balls go, imported each year into Australia, as discussed by the editor recently!

\section{Rating}

- Presentation

- Comprehensiveness

- Readability

- Relevance

- Evidence basis

- Total $16 / 20$

$15 / 20$

$15 / 20$

$16 / 20$

$13 / 20$

$75 / 100$
T Wood

\section{Dying to win}

Edited by B Houlihan. Council of Europe Publishing, 2002, £17.95, softcover, pp 247. ISBN 9287146853

Dying to win gives an eye opening account of the extent to which drugs play a major role in sport. Doping is not new and has been used in sport since ancient Olympic times; it is just that drug use in modern times is at such a level of sophistication, it is now an industry in its own right. The book describes the privileged position sport holds in society, having appeal for both the participant and the spectator. This has led to the massive media interest, commercialism, professionalism, and governmental regulation and manipulation. Economic pressure in the industrialised world and governmental propaganda in the former East Germany, and more recently China, paved the way for the increasing pharmaceutical intervention in sport. With the fall of the GDR, the world saw for the first time what it had long suspected, the extent of systematic doping on a State run basis, and the most interesting fact is that the East Germans kept excellent records! Further, the book takes a look at the next big issue surrounding drugs in sportgenetic engineering.

Dying to win does not just describe the evolution of doping. It explains the complex relation between anti-doping policy, implementation of those policies, and the role of governments, the IOC, and international and national sporting organisations. With the ever increasing involvement of the legal profession, a vicious circle occurs: it becomes too costly for sporting organisations to fight court battles, with their reliance on Government funding depending on results and punishments set in accordance with what will stand up in courts. This all leads to the relative inertia of the governing bodies to be pro-active in the anti-drugs campaign. The inception of the World Anti-Doping Agency (WADA) after the 1998 Tour de France drugs fiasco provided a way forward to standardise and implement anti-doping policy across the world by an independent body.

Problems and solutions to anti-doping policy are addressed. The major problem is inadequate definition of doping - to quote Arthur Gold "The definition lies not in words but in integrity of character.". It is interesting to note that those behind the athlete, namely coach, administrators, medical profession, and scientists, all seem to lose perspective along with their ethics and "integrity of character" when the race for "gold" is on. Dying to win suggests that these people should be held just as accountable as the athletes themselves. Another unfortunate aspect of anti-doping policy is the difficulty in detecting some abused drugs and the fact that these strategies often lag way behind the ability of the pharmaceutical industry to develop new drugs, often for genuine medical reasons but with the unfortunate ability to enhance performance. Education is proposed as a key aspect to anti-doping policy, and parallels with its success in the use of recreational drugs are made. Governments also play a role in limiting supply, decreasing demand for drugs, and the implementation of independent bodies to carry out drug testing. The success of anti-doping policy is also hard to measure. Fewer positive tests may simply reflect a move to less detectable methods rather than a decrease in use, and success may be better measured in terms of fewer world records.

Dying to win gives an accurate account of the problem of doping in sport and the difficulties and complexities in finding solutions to the problems. It makes interesting and provocative reading for all those involved in sport, from the athlete and coach to the sport administrator, the medical profession, and governments. 


\section{Rating}

- Presentation

- Comprehensiveness

- Readability

- Relevance

- Evidence basis

- Total

$17 / 20$

$19 / 20$

$15 / 20$

$18 / 20$

$19 / 20$

$88 / 100$

E Clisby

Chair Drugs in Sport, Sports Medicine Australia; eclisby@healthon-net.com

\section{CALENDAR OF EVENTS}

\section{UK Radiological Congress 2005 (UKRC 2005)}

6-8 June 2005, Manchester, UK

The UK Radiological Congress (UKRC) meeting will encompass the medical, scientific, educational, and management issues that are of interest and relevance to all those involved in the diverse fields of radiological sciences and oncology.

The UKRC provides a forum in which to bring together clinicians, scientists, radiographers, technicians, and other professionals to present and discuss the latest developments and challenges in diagnostic imaging, radiotherapy, and allied radiological sciences.

Key subjects to be covered include: diagnostic radiology; ultrasound; nuclear medicine; interventional radiology; veterinary radiology; emerging technologies; image analysis; computer applications; PACS; radiobiology; radiological physics; management \& audit; computed tomography; magnetic resonance; equipment development.

Expected attendance (conference and exhibition): 4000

Further details: UKRC 2005 Organisers, PO Box 2895, London WIA 5RS, UK; Website: www.ukrc.org.uk; Fax: +44 (0)20 7307 1414; Conference tel: +44 (0)20 7307 1410, Email: conference@ukrc.org.uk; Exhibition tel: +44 (0)207307 1420, Email: exhibition@ukrc. org.uk

\section{1st World Congress on Sports Injury} Prevention

23-25 June 2005, Oslo, Norway

This congress will provide the world's leading sports medicine experts with an opportunity to present their work to an international audience made up of physicians, therapists, scientists, and coaches. The congress will present scientific information on sports injury epidemiology, risk factors, injury mechanisms and injury prevention methods with a multidisciplinary perspective. Panel discussions will conclude symposia in key areas providing recommendations to address the prevention issue in relation to particular injuries and sports.

Further details: Oslo Sports Trauma Research Centre and Department of Sports Medicine, University of Sport and Physical Education, Sognsveien 220, 0806 Oslo, Norway. Email: 2005congress@nih.no; website: www.ostrc.no

\section{Osteosynthese International 2005}

15-17 September 2005, Curiohaus, Hamburg Congress-Chairman: Johannes M. Rueger,

M.D., Professor and Chair Topics:

- Innovations in intramedullary osteosynthesis

- New frontiers in osteoporosis and fracture treatment

- Current trauma research

- Special topic: Recent development in pelvic and acetabular fractures

Abstract submission deadline: 31 March 2005

Further details: INTERCONGRESS GmbH, Martin Berndt, Düsseldorfer Str. 101, 40545 Düsseldorf-Germany. Tel: +49 $211585897-$ 80; fax: +49 211 585897-99; email: martin. berndt@intercongress.de; website: www. osteoint2005.de

\section{4th European Sports Medicine Congress}

13-15 October 2005, Lemesos, Cyprus

Further details: Email: pyrgos.com@cytanet. com.cy

\section{BASEM Conference 2005}

10-12 November 2005, Edinburgh, Scotland Further details: Email: basemoffice@ compuserve.com
BASEM Conference 2006

5-7 October 2006, Oxford, UK

Further details: Email: basemoffice $a$ compuserve.com

\section{CORRECTIONS}

doi: 10.1136/bjsm.2004.00392 1corr l

Cicharro J L, Hoyos J, Gómez-Gallego F, et al. Mutations in the hereditary haemochromatosis gene HFE in professional endurance athletes (Br J Sports Med 2004;38:418-21). The affiliation of $\mathrm{P}$ Celaya was published incorrectly. The correct affiliation is Professional Cycling Team US Postal-Berry Floor. We apologise for this error.

doi: 10.1136/bjsm.2004.000044corr 1

Dadebo B, White J, George K P. A survey of flexibility training protocols and hamstring strains in professional football clubs in England (Br J Sports Med 2004;38:388-94). The multiple regression equation within the Abstract section of this paper was published incorrectly. The correct equation is:

$\mathrm{HSR}=37.79-(0.33 \mathrm{SHT}+10.05 \mathrm{SSP}+2.24 \mathrm{STE})$ $\pm 2.34$

We apologise for this error.

doi: 10.1136/bjsm.2004.010876corr l

Sran M M. To treat or not to treat: new evidence for the effectiveness of manual therapy (Br J Sports Med 2004;38:521-5).

The volume number for reference 23 (Sran et al) was incorrectly published as 24; the correct volume number is 29 .

In Table 2 the results for Giles and Muller should read: Greater short term benefit for back pain with manipulation, but not for neck pain. Acupuncture more effective for neck pain.

In the section "Definitions and search strategy" the first line of paragraph 2 should read: I searched Medline, Cinahl, and Embase databases for randomised clinical trials comparing manual therapy, including spinal joint mobilisation (with or without manipulation) or manipulation only with other conservative treatments for back or neck pain.

We apologise for these errors. 